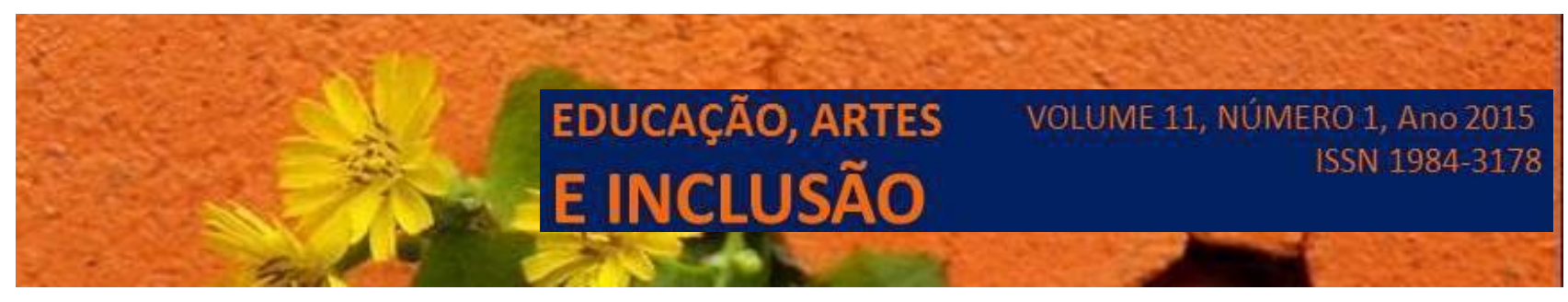

\title{
OS VIDEOGAMES ENQUANTO FORMA DE ARTE ATUAL NA EDUCAÇÃO ESCOLAR
}

DOI: http://dx.doi.org/10.5965/198431781112015089

Walace Rodrigues ${ }^{1}$

\section{RESUMO}

Este escrito busca explorar o mundo dos videogames enquanto arte e enquanto ferramenta pedagógica para a arte-educação. Fazendo relações dos videogames com as artes tecnológicas, como a fotografia e o cinema. Buscando caminhos de aproximação entre arte dentro do campo da história da arte, este artigo intensifica o debate em torno da qualificação dos videogames enquanto objetos de arte. Vários conceitos de tecnologia digital atual são definidos aqui, porém não se faz menção a games específicos para não levantar o debate em relação ao consumerismo e aos direitos autorais. Além destes pontos já mencionados, lembramos dos impactos sociais causados pelos games aos jovens, mudando radicalmente suas rotinas e suas vidas.

Palavras-chave:Videogame; Arte; Arte-Educação.

\begin{abstract}
This paper aims to explore the world of the video games as art and as pedagogical tool to arteducation. This article intensifies the debate regarding the attribution of video games as artworks, making references to video game as technological arts, such as photography and cinema. Looking for ways of approximating between different art forms within the field of art history, this papers intensify the debate in relation to the acceptance of games as artworks. Various concepts of actual digital technology are defined here, but we do not mention specific brands of games to not rise the debate in relation to consumerism and copyrights. After all these mentioned points, we can remember the social impacts caused by the games in the lives of the young people, changing radically their routines and their lives.
\end{abstract}

Keywords: Video games; Art; Art-Education.

\footnotetext{
${ }^{1}$ Doutorando em Humanidades, mestre em Estudos Latino-Americanos e Ameríndios e mestre em História da Arte Moderna e Contemporânea pela Leiden Universiteit (Países Baixos). Professor Assistente da Universidade Federal do Tocantins (UFT).
} 


\section{EDUCAÇÃO, ARTES}

\section{Introdução}

Atualmente, participamos de uma cultura digital da qual não podemos escapar. Em qualquer banco há máquinas computadorizadas para depósitos, saques, transferências, etc.; nosso carro é lavado e secado com o auxílio de sensores; nosso celular envia imagens, mensagens, faz filmes, etc. Enfim, estamos colocados em um mundo de forte cultura digital e nela somos obrigados a nos encaixar.

Da mesma maneira que acontece em nossas vida, acontece em nossos campos de conhecimento. Nas artes vemos novas técnicas e processos artísticos que nos assaltam os sentidos. Somos tomados por uma mundo de virtualidade que se aproxima de nós a cada minuto e que "invade os terrenos" da história da arte.

Assim, novos conhecimentos digitais vão sendo incorporados à nossa vida diária. Esses conhecimentos e mudanças culturais (de hábitos, de ações e de pensares) fazem com que a academia (a instituição pioneira responsável por pensar a sociedade) tenha que rever ou formular novas maneiras de compreender o que acontece nesta sociedade digital.

Desta forma, este artigo tenta compreender um pouco a situação da utilização do videogame ${ }^{1}$ tanto no campo das artes como no campo do ensino das artes no ambiente escolar institucionalizado, buscando intensificar o debate em relação ao seu lugar no mundo da arte e na arte-educação.

\section{Desenvolvimento}

Já nos começos da década de 1960, o canadense Marshall McLuhan se surpreendia com as transformações sociais causadas pela televisão. Ela pode ser vista como o primórdio da tecnologia dos atuais videogames, pois nos invade com o mundo

1 Não vou, neste artigo, mencionar nenhum nome específico de game por causa do valor comercial que têm estes jogos e por suas proteções autorais de uso de nomes e marcas. 


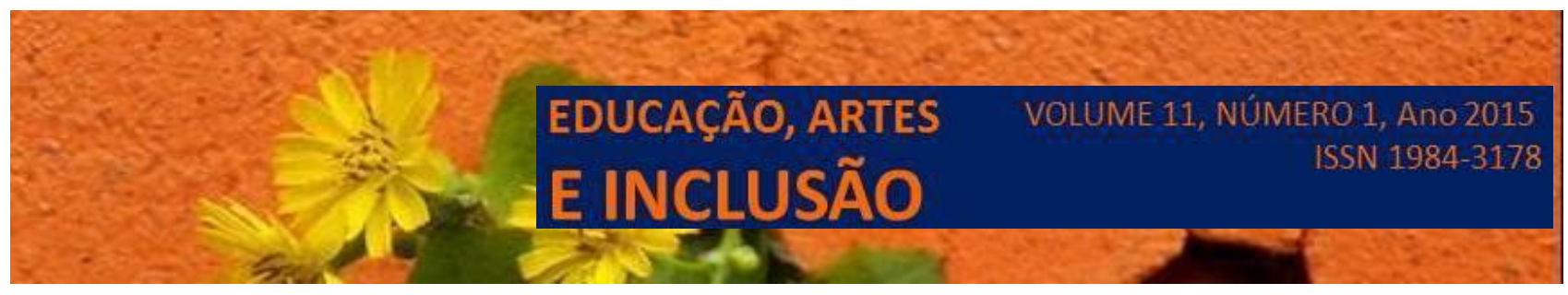

das imagens em movimento, coloridas, mutantes, etc. Décio Pignatari (1997) nos deixa entender o pensamento de McLuhan sobre este ponto:

\begin{abstract}
Segundo Marshall McLuhan, estamos assistindo ao fim da era Gutenberg, ao fim da era iniciada com a criação do código fonético e sistematizada pela invenção de tipos móveis de imprensa, principal responsável, segundo ele, pela destribalização da cultura, pelo individualismo, pelo nacionalismo, pelo militarismo e pela tecnologia ocidental, até a linha de montagem de Ford (que hoje estaria superada). Com o circuito elétrico, que possibilita a ionização ou simultaneidade da informação, termina a era da expansão (explosão) das sociedades e começa a era da "implosão" da informação: a informação complexa, antiverbal, que se manifesta em mosaico, descontínua e simultaneamente - e a televisão é o seu profeta. (PIGNATARI, 1997, p. 13).
\end{abstract}

Nas artes, Andy Warhol se utilizou da televisão como um meio de inspiração para suas obras de arte, reforçando o domínio da informação "complexa, antiverbal, que se manifesta em mosaico, descontínua e simultaneamente", como nos disse Pignatari. O anúncio de Warhol para a empresa japonesa TDK nos deixa ver claramente isto: falando em uma língua estranha para ele e para os norte-americanos, Warhol utilizava-se da televisão como uma máquina que transformava o mundo de então. Neste sentido, era realmente o meio (a televisão) a própria mensagem.

Outro artista importante nas artes ocidentais a explorar o mundo da informação, porém trabalhando mais no campo visual do que no verbal ou escrito, foi Roy Lichtenstein. Ele se inspirou na sociedade de consumo, principalmente nas revistas em quadrinhos (cartuns), para compor seus trabalhos. Uma passagem da escritora e artista Susie Hodge (2009) sobre a estética de Lichtenstein nos deixa ver seus procedimentos artísticos:

Suas obras, geralmente de grandes proporções, são ampliações de detalhes de cartuns ou imagens publicitárias de objetos cotidianos, com contornos pretos muito nítidos e composições dinâmicas. Lembrando cartuns de impressão barata, as figuras recebem cores primárias granuladas com estêncil, técnica nomeada de "Benday Dots" em homenagem ao ilustrador Benjamin Day. Lichtenstein retrata pessoas idealizadas e emprega textos de conteúdo ambíguo. As composições e o uso de cores primárias fortes, ou preto e branco, resultam em imagens singelas porém impactantes (HODGE, 2009, p. 461). 


\section{EDUCAÇÃO, ARTES}

Assim, estas composições de Lichtenstein, retratando pessoas idealizadas e empregando textos de conteúdo ambíguo, parecem dar um dos caminhos visuais possíveis que nos podem levar a compreender melhor a cultura digital da atualidade. Afinal, as imagens dos personagens dos videogames são, geralmente, inspiradas em cartuns e colocadas em lugares extremamente ambíguos e agindo de forma inesperada.

Para entender melhor o que seria a cultura digital, colocamos, aqui, de uma curta definição de Waldenyr Caldas (1986, p. 11) sobre cultura como sendo "o complexo dos padrões de comportamento, das crenças, das instituições e doutros valores espirituais e materiais transmitidos coletivamente e característicos de uma sociedade". Assim, esse sociedade que participa de determinados padrões de comportamento onde as informações são processadas em forma de dígitos por microcomputadores podem ser chamados de pessoas de uma cultura digital.

Segundo Zygmunt Bauman (2001), estamos em tempos de mudanças, de transitoriedades, de transformações, de flexibilizações, do não uniforme, de policentrismos, enfim, em tempos de uma modernidade líquida. Os computadores de última geração e todas as possibilidades trazidas por eles e pela internet fazem parte estruturante de uma cultura digital que muda a todo tempo. Ao final, todos nos aventuramos, uns mais e outros menos, na cultura digital, lugar onde os microcomputadores, os smarthphones, os tablets, etc., são as máquinas indispensáveis e onde a visualidade em 3D oferece maior "realidade" virtual a tudo que vemos na tela.

Podemos dizer que os filmes ou vídeos 3D são suportes tecnológicos onde as imagens são codificadas buscando dar ao espectador a ilusão de uma terceira dimensão espacial. Os filmes 3D trabalham com o extremo uso virtual da altura, da largura e da profundidade. No entanto, a profundidade é dada com o auxílio do uso de perspectivas. As perspectivas são um recurso ótico que nos dá uma falsa noção de profundidade espacial em um plano. 


\title{
EDUCAÇÃO, ARTES
}

Por sua vez, os filmes 4D já são um filme 3D que se utilizam de efeitos especiais como sprays de água para simular chuva ou jatos de vento para simular os ventos de uma tempestade em um ambiente de cinema especialmente preparado para tal. Pode haver vibrações, chuva, vento e luzes estroboscópicas como efeitos em salas especialmente preparadas. Assim, os filmes 4D tentam nos colocar em uma realidade que só pode existir em um mundo virtual. Este mundo virtual pode ser entendido como um mundo paralelo ao nosso mundo "real", como imaginário, como anti-verbal e descontínuo. Colocamos uma passagem de Marita Sturken e Lisa Cartwright (2005) para melhor compreendermos o que é realidade virtual:

\begin{abstract}
Realidade Virtual (RV) é um termo que foi cunhado pelo virtuoso simulador computacional Jaron Lanier para descrever a maneira como usuários experienciam os mundos computacionais gerados pela ciência e nos videogames populares do final da década de 1980 e na década de 1990. Sistemas de realidade virtual incorporam imagem computadorizada, som e sistemas sensoriais para colocar o corpo do usuário em um ciclo de resposta direta com a tecnologia e com os mundos que ela simula. Subjetividade é experienciada na e pela tecnologia. Mais que oferecer um mundo para simplesmente ver e escutar, como faz o cinema, os sistemas de realidade virtual tentam criar uma experiência na qual o usuário se sente como se ele ou ela estivesse fisicamente incorporado, em todos os níveis sensoriais, no mundo representado (STURKEN; CARTWRIGHT, 2005, p. 145, tradução nossa).
\end{abstract}

Também, os vários aparatos necessários, hoje em dia, para jogar um game, como o joystick (controle de videogame caracterizado por uma haste direcional acompanhada de um ou mais botões) ou a sensibilidade virtual de um motion controller (controle de videogame que trás algum tipo de funcionalidade baseada na captura de movimentos) fazem com que os videogames sejam cada dia mais apreciados e estejam mais próximos de nossos sentidos.

Ainda, o mundo virtual pode ser entendido como um mundo que se opõe (e se relaciona) ao mundo da realidade vivenciada pelos nossos sentidos. O mundo virtual é um mundo criado pelo homem com o auxílio das ferramentas tecnológicas, sendo um mundo que existe em potência e não em ação (para utilizar termos filosóficos), é um mundo criado ou simulado através de meios eletrônicos avançados. 


\section{EDUCAÇÃO, ARTES}

Mesmo com toda esta tecnologia digital, as bases da realidade virtual, ao nível da visualidade, ainda são dadas com o auxílio das técnicas de perspectiva. A perspectiva pode ser entendida como uma técnica artística de simular as distâncias espaciais da realidade em um desenho (ou em outra forma de representação), ela é uma aparente probabilidade de representação que busca figurar as dimensões espaciais do real.

Os egípcios se utilizavam da lei da frontalidade como técnica perspectiva para representar o homem de seu tempo. Os gregos já conheciam as técnicas de perspectiva linear de um ou vários pontos, onde se utilizavam linhas que convergem para um ponto central ou para pontos diferentes. Essas são somente algumas técnicas de representação onde as técnicas de perspectiva foram empregadas, conforme nos informa Alcídio M. de Souza (1970):

O artista não está obrigado a restringir-se a um determinado sistema. Os vários tipos de perspectiva - e há outros não mencionados aqui - são apenas recursos de cuja utilização pode ou não servir-se o artista. É lícito a este, igualmente, utilizar-se de um ou mais níveis de visão, no mesmo quadro, de modo a dar ênfase a certos objetos ou criar um impressão incomum do espaço (SOUZA, 1970, p. 23-4).

$\mathrm{Na}$ atualidade, notamos, através das atividades práticas, que os estudantes mais jovens que 19 anos e que se utilizam corriqueiramente de videogames estão muito familiarizados com as técnicas de perspectiva linear, de um ou vários pontos de fuga. Eles conseguem desenvolver desenhos utilizando a perspectiva linear de forma exemplar, mesmo sem nunca terem sido informados sobre elas.

Vale lembrar que as técnicas de desenho com a utilização da perspectiva linear são técnicas inventadas, elas tentam reproduzir a realidade de forma mais próxima possível da realidade espacial, buscando subjugar a espacialidade real à uma superfície plana.

Podemos dizer que a espacialidade é a qualidade daquilo que se refere ao espaço, a aquilo que nos contêm e envolve o mundo que nos cerca. Nossa relação com o 


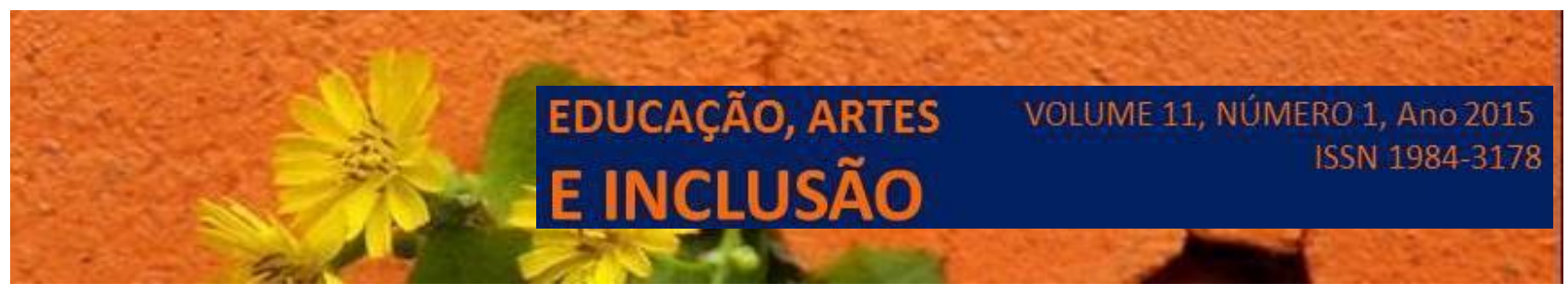

espaço pode ser compreendida através da formulação de Howard Gardner sobre a "inteligência espacial" ou, alternativamente, como um processo de aprendizado. Preferimos acreditar ser possível utilizar-se um pouco de cada uma destas duas teorias sem basear-se somente em uma.

Além disto, os estudos de Isabela Granic, Adam Lobel e Rutger C. M. E. Engels, pesquisadores da Universidade Radboud, de Nijmegen, nos Países Baixos, mostram os benefícios de jogar videogames em relação à uma melhor compreensão da espacialidade e da resposta mental a um estímulo, conforme passagem abaixo:

\begin{abstract}
Ao contrário do que convencionalmente se acredita que jogar videogames é intelectualmente preguiçoso e sedativo, jogar estes jogos promove um largo número de habilidades cognitivas. Isto é particularmente verdade para os videogames de tiro (geralmente chamados de "action" games pelos pesquisadores), muitos dos quais são violentos em natureza (como Halo 4, Grand Theft Auto IV). A evidência mais convincente vem de inúmeros estudos de treinamento que recrutam gamers inocentes (aqueles que dificilmente ou nunca jogam videogames violentos) e fazem-nos, aleatoriamente, jogar tanto um jogo de tiro quanto outro tipo de videogame pelo mesmo período de tempo. Comparado a um grupo controle, aqueles que jogam um videogame de tiro mostram ser mais rápidos e precisos à alocação de atenção, eles têm melhor compreensão espacial no processamento visual e maior habilidade de rotação mental (GRANIC, LOBELS; ENGELS, 2014, p. 68, tradução do autor).
\end{abstract}

Ainda, estes mesmos pesquisadores verificaram que a geração de crianças e adolescentes atuais (os "nativos digitais") que se utilizam dos videogames, além de terem uma excelente melhora na apreensão de espacialidade (habilidade fundamental no processo de criação artística), melhoram, também, suas habilidades de resolução de problemas, conforme a passagem abaixo:

Em adição às habilidades espaciais, pesquisadores têm especulado, também, se videogames são um excelente meio para o desenvolvimento da habilidade de solução de problemas (Prensky, 2012). Realmente, a resolução de problemas parece ser central a todos os gêneros de videogames (incluindo aqueles de conteúdo violento). Os jogos de quebra-cabeça variam em complexidade desde achar a tora mais rápida entre $\mathrm{A}$ e $\mathrm{B}$ a descobrir sequências de ações complexas baseadas em memorização e habilidades analíticas. Além disto, designers de games geralmente oferecem poucas instruções sobre como resolver os problemas nos videogames, deixando os jogadores com uma quase branca paleta para explorar uma imensa variedade de possíveis soluções baseadas em experiências passadas e intuições. Prensky (2012) argumenta que a exposição a estes tipos de games com problemas 


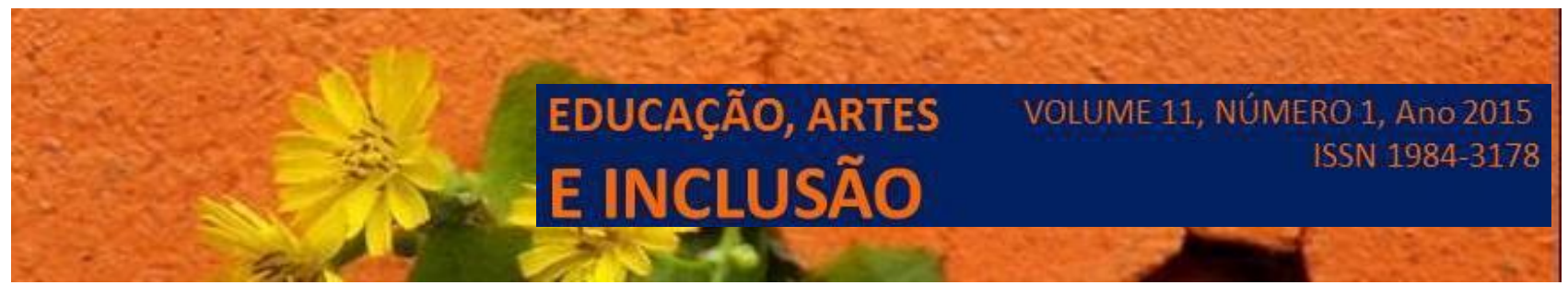

abertos (e outras experiências aprendidas na Internet) tem influenciado uma geração de crianças e adolescentes que vêm crescendo como "nativos digitais". Ao contrário de aprender pela instrução linear explícita (como lendo, primeiramente, um manual), muitas crianças e jovens resolvem problemas através de tentativas e erros, recursivamente recolhendo provas que eles testas pela experimentação. Somente dois estudos tem testado explicitamente a relação entre jogar videogames e as habilidades de resolução de problemas; em ambos, a resolução de problemas foi definida no senso refletivo (como ter tempo para juntar informações, avaliar várias opções, formular um plano e considerar estratégias mutantes e/ou objetivos antes de seguir adiante) (Idem, p. 69, tradução do autor).

Howard Gardner acredita, também, que há varias competências humanas relativamente autônomas, e que são por ele chamadas de "inteligências humanas". Sua teoria sobre as inteligências múltiplas parece difícil de ser negada, já que notamos aptidões específicas destas inteligências em cada um de nós. Além disto, tais inteligências (linguística, musical, lógico-matemática, espacial, corporal sinestésica, interpessoal, intrapessoal e naturalista) podem ser combinadas, de várias maneiras, pelos indivíduos.

Interessa-nos, aqui, compreender um pouco mais sobre a inteligência espacial, por isso utilizamo-nos de uma passagem de Valéria da Hora Bessa (2008) sobre esta inteligência dentro da teoria de Gardner:

Centrais à inteligência espacial estão as capacidades de perceber o mundo visual com precisão, efetuar transformações e modificações sobre as percepções iniciais e ser capaz de recriar aspectos da experiência visual, mesmo na ausência de estímulos físicos relevantes. Pode-se ser solicitado a produzir formas ou simplesmente manipular as que foram fornecidas. Essas capacidades são claramente não idênticas: um indivíduo pode ser arguto em percepção visual, embora tenha pouca capacidade para desenhar, imaginar ou transformar um mundo ausente. A operação mais elementar sobre a qual outros aspectos da inteligência espacial se baseiam é a capacidade de perceber uma forma ou um objeto. Uma vez que somos solicitados a manipular a forma ou o objeto apreciando como ele será apreendido de outro ângulo de visão ou como pareceria se fosse girado, entramos completamente na esfera espacial, pois uma manipulação no espaço foi necessária. Problemas de dificuldade ainda maior podem ser propostos no domínio "objeto" ou "figura". De fato, problemas no ramo matemático da topologia requerem precisamente a capacidade de manipular formas complexas em várias dimensões. A inteligência espacial acarreta algumas capacidades: a de reconhecer exemplos do mesmo elemento; a de transformar ou reconhecer uma transformação de um elemento em outro; a de evocar formas mentais para então transformá-las; a capacidade de produzir uma representação gráfica de informações espaciais, e similares (BESSA, 2008, p. 144-5). 


\section{EDUCAÇÃO, ARTES}

Partindo da inteligência espacial, essa manipulação perspectiva exemplar do espaço é extremamente importante no campo das artes, sendo o que destacamos aqui como uma das grandes vantagens de se trabalhar com os videogames em sala de aula e incentivar os estudantes a utilizá-los (não de forma abusiva ou viciosa).

O uso dos games podem ajudar no desenvolvimento da inteligência espacial. Um exemplo que parece inocente mas que mostra como a inteligência espacial é importante é quando entramos em um elevador e vemos aquela pessoa sozinha naquele espaço e parada no meio do elevador ou na entrada: isto parece demonstrar um parco uso de sua inteligência espacial e fraca percepção do espaço a sua volta. Uma pessoa que se utiliza dos games dificilmente bloquearia o espaço de manobra física no elevador.

Ainda, sobre os tipos de games, eles podem ser de ação, de aventura, de tática e de metas a serem alcançadas. O uso de técnicas de estratégias dos games faz com que os jovens aperfeiçoem suas inteligências lógico-matemáticas. Planejar o ataque perfeito ou caminho menos arriscado são exercícios de pura lógica, o que incita o pensar crítico de resolução de problemas.

Também, se torna mais fácil para os jovens aprenderem a língua inglesa através dos games do que em suas aulas de inglês na escola. Geralmente as aulas de inglês da escola englobam um vocabulário fraco e estruturas básicas da língua, ao contrário dos games, que se utilizam de um linguajar corrente e atual.

Os Parâmetros Curriculares Nacionais de Arte (do terceiro e quarto ciclos do ensino fundamental) nos deixa ver claramente que as inovações tecnológicas devem ser utilizadas no âmbito dos temas transversais escolar e que os professores de artes têm a função de compreender as mudanças que cocorem na esfera sociocultural dos seus estudantes e utilizá-las em suas aulas:

Em conjunto com as outras áreas de conhecimento trabalhadas na escola, na área de Arte pode-se problematizar situações em que os alunos tenham oportunidade de perceber a multiplicidade de pensamentos, ações, atitudes, 


\section{EDUCAÇÃO, ARTES \\ VOLUME 11, NÚMERO 1, Ano 2015 E INCLUSÃO

valores e princípios relacionados, à ética; meio ambiente; orientação sexual; saúde; trabalho, consumo e cidadania; comunicação e tecnologia informacional; pluralidade cultural, além de outros temas locais definidos na organização escolar. Para trabalhar os temas transversais na área de Arte, deve-se ainda levar em consideração as especificidades da área, procurando nos conteúdos aspectos que os integrem a ela. É preciso ressaltar, ainda, que a elaboração e apreensão de noções, princípios e valores pelos alunos sobre as práticas de arte e questões emergentes do processo sociocultural se faz na interação com os professores (BRASIL, 1998, p.38).

E para aqueles que pensam que o uso de aparatos tecnológicos é somente para adultos, a Lei de Diretrizes e Bases da Educação Nacional (Lei 9394), alterada pela Lei 11.274, de 2006, deixa ver claramente que as crianças devem ser orientadas para a compreensão do ambiente tecnológico que as cerca, conforme o artigo abaixo:

Art. 32. O ensino fundamental obrigatório, com duração de 9 (nove) anos, gratuito na escola pública, iniciando-se aos 6 (seis) anos de idade, terá por objetivo a formação básica do cidadão, mediante: (Redação dada pela Lei ${ }^{\circ}$ 11.274, de 2006)

I - o desenvolvimento da capacidade de aprender, tendo como meios básicos o pleno domínio da leitura, da

escrita e do cálculo;

II - a compreensão do ambiente natural e social, do sistema político, da tecnologia, das artes e dos valores

em que se fundamenta a sociedade;

III - o desenvolvimento da capacidade de aprendizagem, tendo em vista a aquisição de conhecimentos e

habilidades e a formação de atitudes e valores;

IV - o fortalecimento dos vínculos de família, dos laços de solidariedade humana e de tolerância recíproca em

que se assenta a vida social (BRASIL, 1996, Art. 32).

Também, a mesma Lei de Diretrizes e Bases, quando tratando da educação no ensino médio, direciona para um uso prático das tecnologias atuais, visando “...a compreensão dos fundamentos científico-tecnológicos dos processos produtivos, relacionando a teoria com a prática, no ensino de cada disciplina" (BRASIL, 1996, Art. 35, IV). E a avaliação, neste nível de ensino, deve verificar, também, o 


\title{
EDUCAÇÃO, ARTES
}

"...domínio dos princípios científicos e tecnológicos que presidem a produção moderna" (Idem, Art. 36, § $1^{\circ}$, I).

Além da exposição da obrigatoriedade legal do usos das novas tecnologias na escola, verifica-se que os games parecem deleitar estética e ludicamente as crianças e jovens que os utilizam, podendo, algumas vezes, "viciar" de prazer os usuários. Utilizamos uma passagem do filósofo Paulo Ghiraldelli Júnior (2010) sobre o prazer que a experiência estética pode nos causar:

\begin{abstract}
...Kant supôs que a arte deveria dar prazer, mas que este seria como um prazer desinteressado, daí uma gratificação tépida, uma vez que sem conexão com a satisfação de necessidades reais ou realização de objetivos reais. Assim, isso seria uma espécie de prazer narcotizado, o prazer que consiste em ausência de dor, que é exatamente o pensamento de Shopenhauer de que o valor da arte deve repousar na liberdade que ela promete separando-nos das urgências da vida real (GHIRALDELLI JR, 2010, p. 107).
\end{abstract}

A passagem acima exemplifica bem a conexão filosófica entre a experiência estética e o prazer daqueles que se utilizam dos videogames. Além disto, os games, baseados em mundos virtuais, realmente nos separam das urgências da vida cotidiana, da realidade que nos oprime, e nos levam a um deleite verdadeiramente estético.

Também, o conceito de videogame e seu reconhecimento enquanto arte pode ser relacionado ao readymade de Marcel Duchamp. Ambos têm na novidade tecnológica a armadilha do artístico. Duchamp colocou seu famoso urinol em exposição em 1917, chocando o comitê da Sociedade de Artistas Independentes. Esta inusitada atitude do artista refletiu em mudanças radicais em relação ao que se concebia como arte na época, e ainda hoje nos faz refletir. Essa informação cruza com a de algum dos teóricos que estruturam a pesquisa?

Há, também, hoje em dia, a controvérsia em relação a classificar os videogames enquanto arte. É certo que os videogames são um meio tecnológico muito recente e que a maioria dos críticos e especialistas de arte acham "novidades" extremamente alarmantes. O mesmo aconteceu com o cinema, uma forma de arte que, 


\section{EDUCAÇÃO, ARTES}

em seu princípio, era somente valorizada enquanto um avanço tecnológico, da vitória do homem e de suas máquinas sobre a natureza. No entanto, o cinema se firmou, paulatinamente, enquanto arte durante o século XX.

O processo de aceitação do cinema como uma linguagem artística demorou décadas. $\mathrm{O}$ cinema também se utiliza de várias outras artes e técnicas artísticas para estruturar-se: como do teatro, da iluminação, da cenografia, da fotografia, do vestuário, etc. Arnold Hauser (1998), em uma análise sociológica em relação ao cinema, nos deixa ver nosso "despreparo" de compreender as novas formas de arte: "A unidade cooperativa de cinema antecipa uma técnica social para a qual ainda não estávamos aptos, assim como a câmera, ao ser inventada, antecipou uma técnica artística da qual ninguém, à época, conhecia realmente o alcance e o poder” (HAUSER, 1998, p. 980).

Uma outra forma de arte que nos tomou de surpresa foi a videoarte, forma de arte que se utiliza de vídeos pensados e produzidos enquanto objetos de arte, começou a tomar força na década de 1960 e hoje é uma forma de arte com status próprio. Exposições de objetos de videoarte são comuns, hoje em dia, em grandes bienais e exibições atuais.

Neste sentido, acreditamos que os games serão, futuramente, reconhecidos como trabalhos artísticos, objetos para além do entretenimento e que utilizam várias artes para compor-se e da estética do prazer para firmar-se enquanto trabalhos de arte.

Nesta mesma linha de pensamento de games enquanto arte vale informar que, em 2009, o Instituto Itaú Cultural2 colocou onze televisões de plasma na parede de uma galeria, cada uma com um jogo (game) e os chamou de obra de arte. A "ousada" exposição se intitulou "GamePlay", com um apelo claro à ludicidade dos games e ao fascínio tecnológico que estes exercem sobre, principalmente, a geração mais jovem.

2 O Instituto Itaú Cultural é um centro voltado para os eventos artísticos e culturais. Fundado em 1987, esta instituição abriga várias exposições e eventos artísticos temporários e se localiza na cidade de São Paulo. 


\section{EDUCAÇÃO, ARTES}

Nesta época de globalização e de utilização de vários suportes e técnicas como obras de arte, não podemos descartar o videogame como um objeto de arte. Até podemos dizer: como objeto de arte participativa, como preconizaram os artistas brasileiros neoconcretos (como Hélio Oiticica, Lygia Clark e Lygia Pape). A excelente qualidade gráfica dos videogames atuais, seu preciosismo na composição de personagens e ambientes virtuais e a identidade visual própria de cada game fazem com que eles, verdadeiramente, possam ser chamados de arte.

Vale lembrar, ainda, que exibições de videogames enquanto forma de arte têm acontecido em vários museus norte-americanos desde os princípios da década de 1990. Neste país o videogame já é aceito como uma forma de arte em si. O Smithsonian American Art Museum de Washington promoveu uma exibição, no ano de 2012, intitulada "The Art of Video Games" (A Arte dos Videogames) e que foi pensada para demonstrar a artisticidade dos videogames e sua influência criativa.

Não podemos esquecer, também, o impacto cultural e social que os videogames provocaram e provocam na vida dos jovens. Houve uma mudança drástica de atividades sociais e a formação de específicos grupos culturais ligados aos games. $\mathrm{O}$ tempo gasto jogando videogames é tempo que se retira de outras atividades, assim, a importância dada aos games passa a ser central na vida de vários jovens, reavaliando a importância das atividades a que se dedica. O problema do "prazer narcotizado", como nos bem disse Ghiraldelli Jr., é quando ele vira uma atividade viciosa e nos paralisa as outras atividades da vida.

\section{O psiquiatra e professor da Pontifícia Universidade Católica de São Paulo} Haim Grunspun (2001), em seu artigo "Games violentos não fazem mal?", desmascara as acusações falsas de que os games causam alienação e violência:

Enquanto os jogos eletrônicos são uma diversão fácil e prazerosa para as crianças - que não precisam de nenhum curso para se tornarem experts no assunto -, os adultos têm mais dificuldade para jogar. E, por isso, os encaram como algo desconhecido e ameaçador. Desconfio que essa é a origem das acusações do tipo: "as crianças passam tempo demais diante do videogame"; "os jogos são alienantes"; "prejudicam o desenvolvimento infantil”; e, o mais 
recorrente: "a violência desses jogos pode desencadear uma onda de agressividade em nossa sociedade".

"Tenho 73 anos, sou avô de cinco netos e acompanho a evolução do videogame desde os seus primórdios. Nunca soube de nenhuma epidemia de violência que pudesse ser atribuída a esse tipo de diversão. Nem de abuso de drogas e álcool decorrentes desses jogos. E não adianta citar aqueles casos de um jovem que estourou os miolos de seus colegas de escola dizendo que foi influenciado por um jogo sanguinolento. Sou psiquiatra, advogado e sei o que é um distúrbio mental, assim como sei que, depois de um surto de psicose acompanhado de violência, até o Tom \& Jerry pode ser culpado. Afinal, eles também tinham sua dose de perversão. É só lembrar as cenas cruéis em que o Jerry coloca fogo no rabo do Tom ou em que esfola a sua pele. E tudo era motivo de gargalhadas". (GRUSPUN, 2001, s/p).

Também, vale lembrar que os videogames utilizam-se de várias linguagens em sua composição, tais como a matemática, a visual, a gráfica, a verbal, a plástica, a corporal, entre outras. Essas linguagens trabalham de forma relacional, uma sempre se relacionando com a outra, e produzindo este efeito que Pignatari chamou de informação "complexa, antiverbal, que se manifesta em mosaico, descontínua e simultaneamente".

A geração atual $(Z)$ é uma geração que consegue executar várias atividades ao mesmo tempo: escutar música, escrever um texto no computador, participar de uma rede social, jogar um game, etc. Isto era algo impensável para as gerações anteriores. As gerações Y, (nascidos entre 1980 e 2000), W (é uma subdivisão da geração Y e se refere aos nascidos entre 1990 e 2000) e a Z (nascidos entre 1990 e 2010) têm uma clara relação com a alta conectividade às pessoas através dos vários mecanismos da internet.

Ainda, os videogames remetem às demandas culturais por diversão e entretenimento destas gerações mais atuais. Os videogames surgiram como objetos culturais determinados por uma sociedade jovem que os consumia e os faziam ter sucesso comercial ou não. Há games que se tornaram emblemáticos de determinada época das ciências computacionais e de determinado grupo cultural, já que os avanços gráficos, de som e de materiais, etc., determinaram uma estética específica dos games em relação ao desenvolvimento tecnológico de seu tempo. 
Mais um ponto a acrescentar seria o advento de uma nova área de estudos relacionada diretamente aos games e que é chamada, em língua inglesa, de "Machinima". Martin Picard (2006), da Universidade de Montreal, nos define este novo campo de estudos:

\begin{abstract}
Machinima é geralmente associada com o mundo do videogame, principalmente por causa das ferramentas e definições para produzir Machinima que vieram da industria dos games, e Machinima é quase exclusivamente criada pela comunidade de gamers. No entanto, Machinima é, também, facilmente associada com cinema digital, já que as técnicas de produção de Machinima são similares às práticas de fazer filmes. Não obstante, o estudo de Machinima como uma nova forma ou movimento ocorreu, principalmente, a partir das novas mídias e dos estudos de arte digital. (PICARD, 2006, s/p, tradução nossa).
\end{abstract}

O termo "Machinima" foi criado da junção das palavras machine (máquina) e cinema (produção de filmes), ambas em língua inglesa, e ele pode ser definido como as técnicas de produção que se utilizam da computação gráfica em computadores domésticos, ou mesmo como um próprio filme executado com estas técnicas. Enquanto um gênero fílmico específico, "Machinima" se refere a um filme criado através de ferramentas e recursos disponíveis em games caseiros.

Agora, focando-nos no ambiente escolar, as escolas, principalmente nas aulas de artes, devem incluir os videogames enquanto técnica artística e enquanto linguagem visual-letral-sonora-virtual (sendo esta multi-linguagem uma característica do século XXI). Os Parâmetros Curriculares Nacionais em Arte, de 1998, já mencionavam a incorporação das novas tecnologias no ambiente escolar:

As artes visuais, além das formas tradicionais - pintura, escultura, desenho, gravura, arquitetura, objetos, cerâmica, cestaria, entalhe —, incluem outras modalidades que resultam dos avanços tecnológicos e transformações estéticas do século XX: fotografia, moda, artes gráficas, cinema, televisão, vídeo, computação, performance, holografia, desenho industrial, arte em computador. Cada uma dessas modalidades artísticas tem a sua particularidade e é utilizada em várias possibilidades de combinações entre elas, por intermédio das quais os alunos podem expressar-se e comunicar-se entre si e com outras pessoas de diferentes maneiras. (BRASIL, 1998, p. 63). 


\section{EDUCAÇÃO, ARTES}

Os games podem, portanto, entrar nas aulas de artes como uma linguagem artística que busque desenvolver novas formas de pensar e ver o mundo, favorecendo uma aprendizagem altamente significativa para os estudantes. A professora Simone Selbach (2010) nos fala da importância de utilizarmos nas aulas de artes várias formas de linguagens artísticas e para explorar novos saberes:

Uma aula de Artes que explora o tema proposto a partir de linguagens diferentes usa os saberes existentes na estrutura cognitiva do aluno par mostrar novos saberes, que o ajuda a associar o apreendido às suas emoções, e clarifica o que se expõe; com uma nítida organização, é sempre uma aula com conteúdos mais fáceis de ser lembrados (SELBACH, 2010, p. 27).

Vale lembrar aqui o impacto social que os videogames causaram na rotina da juventude atual. Horários foram mudados para caber períodos para jogar videogames. A vida real dos jovens passou a ser mais descontínua e de atividades simultâneas. Os games passaram a ter uma força importante nesta mudança de hábitos.

O que desejamos ressaltar aqui é que esta mudança pode não ser tão negativa quanto parece a muitas pessoas, já que os games ajudam a desenvolver outras habilidades (atenção, raciocínio lógico, estratégias, línguas, entre outras) nos jovens de hoje, algo que não se fazia desta forma há algumas poucas décadas atrás. Vendo os videogames como uma ferramenta de uso artístico (aqui lembramos que toda ferramenta deve ser usada em tempo certo e com cuidados específicos), para desenvolver habilidades específicas, podemos melhor entendê-los como um aliado na educação escolar em artes e não como um inimigo.

\section{Considerações finais}

Neste texto buscamos tratar dos benefícios de uma ferramenta típica da cultura digital atual, que é o videogame. Buscamos compreender os benefícios dos 


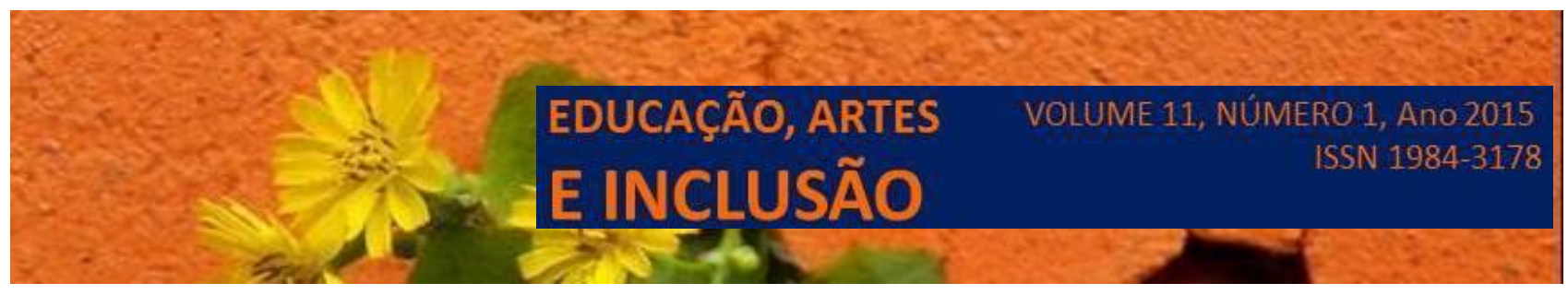

games para a sensibilização em relação à espacialidade, uma especialidade atual que é marcada pelo hábito com o mundo virtual e com novas formas de olhar.

A facilidade dos utilizadores de games na compreensão de perspectivas construídas, tais como as perspectivas com vários pontos de fuga, mostram que há benefícios para o uso de videogames em arte-educação, e que estes games não devem ser desprezados enquanto elementos culturais que atingiram nossa juventude atual. Outra passagem de Haim Grunspun (2001) nos mostra, definitivamente, o resultado de suas pesquisas sobre aqueles que utilizam e utilizaram videogames:

Como psiquiatra pude comprovar a falsidade dos males provocados pelos videogames depois de fazer algumas pesquisas. Os dados mostraram que esses jogos, na verdade, ajudavam no desenvolvimento da personalidade das crianças, principalmente entre os meninos $(80 \%$ dos aficionados pelos jogos são homens). Constatei que a maioria dos adultos que jogaram videogame na infância e na adolescência fizeram cursos em áreas de exatas, administração e comunicação. E quase todos concordaram que o videogame aumentou suas habilidades em estratégia e lógica. (GRUSPUN, 2001, s/p).

Assim, os games podem ser uma boa ferramenta para a vida futura dos jovens, fazendo com que eles se posicionem de maneira crítica, construtiva e responsável em várias situações sociais, além de incrementar habilidades específicas.

Também, as pesquisas de Isabela Granic, Adam Lobel e Rutger C. M. E. Engels (2014) mostram que, no ramo da psicologia cognitiva-behaviorista, os videogames tem uma vasta gama de utilidades para problemas de saúde física e mental, conforme a seguinte passagem:

Videogames asseguram um imenso potencial para ensinar novas formas de pensamento e comportamento. Nós acreditamos que esse potencial de aprendizado tem sido largamente inexplorado na área da saúde mental, e abordar esta lacuna detêm uma grande promessa para uma nova e radical abordagem para intervenção (GRANIC, LOBELS; ENGELS, 2014, p. 75, tradução do autor). 


\section{EDUCAÇÃO, ARTES \\ VOLUME 11, NÚMERO 1, Ano 2015 \\ E INCLUSÃO

Finalizando, podemos dizer que todo jogo é lúdico porque insere o jogador no mundo das regras sociais de convivência grupal, ajudando-o a se adaptar a determinado grupo social, dai o videogame ser um aliado dos jovens no entendimento das regras de sua própria sociedade, vislumbrando claramente os limites entre o real e o virtual, valorizando o respeito ao próximo e treinando este jovens nas regras a serem obedecidas no jogo real da vida.

Além disto, está provado, a partir de pesquisas na área da psicologia onde está essa informação?, que os jogadores de videogames desenvolvem várias habilidades mentais de forma mais acentuadas do que aqueles que não jogam games. Os gamers são mais atentos, desenvolvem uma ótima compreensão espacial a partir do processamento visual e são mentalmente mais lógicos, entre outros benefícios. Partindo destas habilidades intimamente ligadas à criação artística e à compreensão de obras de arte, podemos verificar que os videogames abrem um novo e excitante campo de experimentação educacional, enquanto técnica pedagógica e artística, no ensino escolar de Artes.

\section{Referências bibliográficas}

BAUMAN, Zygmunt. Modernidade líquida. Rio de Janeiro: Zahar, 2001.

BESSA, Valéria da Hora. Teorias da aprendizagem. Curitiba: IESDE Brasil S.A., 2008.

BRASIL. Lei de Diretrizes e Bases da Educação Nacional. Lei 9394, de 20 de dezembro de 1996, com alterações até 2014. Presidência da República, Casa Civil, Subchefia para Assuntos Jurídicos, Brasília: MEC, 1996.

Secretaria de Educação Fundamental. Parâmetros Curriculares Nacionais: Arte. Terceiro e quarto ciclos de Ensino Fundamental. Secretaria de Educação Fundamental. Brasília : MEC, SEF, 1998. 


\section{EDUCAÇÃO, ARTES}

VOLUME 11, NÚMERO 1, Ano 2015 E INCLUSÃO

GRIRALDELLI JR, Paulo. História essencial da filosofia. São Paulo: Universo dos livros, 2010.

GRUSPUN, Haim. Games violentos não fazem mal?. IN Revista Super Interessante. Editora Abril, março, 2001, acessado em 02/06/2014, disponível em < http://super.abril.com.br/tecnologia/games-violentos-nao-fazem-mal-442032.shtml >

CALDAS, Waldenyr. Cultura. São Paulo: Global, 1986.

GRANIC, Isabela; LOBEL, Adam; ENGELS, Rutger. The Benefits of Playing Video Games. IN: American Psychologist. January 2014. American Psychological Association, Vol. 69, No. 1, pág. 66-78.

HAUSER, Arnold. História social da arte e da literatura. São Paulo: Martins Fontes, 1998.

HODGE, Susie. Roy Lichtenstein. IN: 501 grandes artistas. FARTHING, Stephen (ed.). Rio de Janeiro: Sextante, 2009, p. 461.

PICARD, Martin. Machinima: Video Game As An Art Form? Canadian Games Study Association CGSA Symposium, 2006.

PIGNATARI, Décio. Informação Linguagem Comunicação. 19ª ed. São Paulo: Cultrix, 1997.

SELBACH, Simone (supervisão geral). Arte e didática. Petrópolis: Vozes, 2010. Coleção Como Bem Ensinar, coordenação de Celso Antunes, vários autores.

STURKEN, Marita; CARTWRIGHT, Lisa. Practices of looking: an introduction to visual culture. New York: Oxford University Press, 2005.

SOUZA, Alcidio M. de. Artes Plásticas na Escola. $3^{a}$ ed. Rio de Janeiro: Bloch Editores S. a, 1970. 